\title{
Management of Pediatric Appendiceal Carcinoid Tumor: A Single-center Experience
}

\author{
(1) Sefa SAĞ, 1 (D) Burcu KEMAL OKATAN² \\ 'Department of Pediatric Surgery, University of Health Sciences, Trabzon Kanuni Training and Research Hospital, Trabzon-Turkey \\ ${ }^{2}$ Department of Pathology, University of Health Sciences, Trabzon Kanuni Training and Research Hospital, Trabzon-Turkey
}

\begin{abstract}
OBJECTIVE
Appendiceal carcinoid tumor (ACT) is a rare tumor in children. Standard management guidelines in children have not been established due to the rarity of carcinoid tumors in children. The aim of the study was to present our experience in the management of ACT in children.
\end{abstract}

\section{METHODS}

Medical records of all pediatric patients treated at our institution for ACT between June 2015 and June 2020 were reviewed retrospectively. Demographic characteristics, histopathological examination, and follow-up records were reviewed for each patient.

\section{RESULTS}

Eight $(0.94 \%)$ out of 843 children who underwent appendectomy during the study period were detected with histological evidence of ACT and were included in the study. Median tumor size was 0.35 (range, $0.1-1) \mathrm{cm}$. The tumor had invaded the muscularis propria in $4(50 \%)$, the submucosa in $2(25 \%)$, the subserosa in $1(12.5 \%)$, and the mesoappendix in $1(12.5 \%)$ patient. All the patients had tumor-free margins and none of them had lymphadenopathy at diagnosis. Mitotic index and Ki67 levels were $>2$ in two patients. Only appendectomy was performed in all patients. No recurrence was observed in any patient throughout the follow-up period. Patients were followed up for a mean $\pm S D ; 41.2 \pm 11.1$ months.

\section{CONCLUSION}

ACT is a rare tumor in children usually presenting as an incidental finding during the histopathological examination of appendectomy specimen. Follow-up of histopathological results after appendectomy is of paramount importance. Appendectomy is curative, particularly in tumors smaller than $2 \mathrm{~cm}$ in diameter, and the clinical outcome is excellent after appendectomy.

Keywords: Appendectomy; carcinoid tumor; child.

Copyright $\odot$ 2022, Turkish Society for Radiation Oncology

\section{Introduction}

Appendiceal carcinoid tumor (ACT) is a rare tumor in children usually presenting as an incidental finding during the histopathological examination of appendectomy specimen. The incidence of ACT in resected specimens has been shown to range from $0.08 \%$ to $0.7 \% \cdot[1,2]$
Standard management guidelines in children have not been established due to the rarity of carcinoid tumors in children. The most of the algorithms available in the literature have been developed from adult experiences but these tumors appear to behave differently in children.[3]

The aim of this study was to review our experience in children with ACT and to compare and evaluate the 
incidence, epidemiology, and management of ACT in light of the literature.

\section{Materials and Methods}

All pediatric patients (aged below 18 years) who had undergone appendectomy for suspected appendicitis in our hospital between June 2015 and June 2020 were reviewed retrospectively. The diagnosis of ACT was based on histopathological examination. Demographic characteristics, histopathological findings, treatment modalities, and follow-up records of the patients with ACT were evaluated. An ethical approval was obtained from the local ethics committee (No: 2020/59).

All the analyses were performed using SPSS for Windows version 22.0 (Armonk, NY: IBM Corp.). Continuous variables were expressed as median (range) and categorical variables were expressed as percentages (\%).

\section{Results}

A total of 843 pediatric patients who underwent appendectomy for the treatment of clinically suspected appendicitis during the study period were analyzed. Of these, $8(0.94 \%)$ patients who were detected with histological evidence of ACT were included in the study. The eight patients comprised $5(62.5 \%)$ boys and 3 (37.5\%) girls. Mean age at diagnosis was $12.9 \pm 3.6 \mathrm{SD}$ years. All patients had symptoms of acute appendicitis. Abdominal pain, nausea, and vomiting were the most common presenting symptoms. No patient had flushing, diarrhea, Cushing's syndrome, or carcinoid syndrome. Ultrasonography (US) confirmed the presence of appendicitis in all patients.

In all cases, hematoxylin and eosin stained sections showed typical features of the carcinoid tumor (Fig. 1) and immunohistochemistry showed strong positivity for chromogranin (Fig. 2). Median tumor size was 0.35 (mean, $0.45 \pm 0.33$; range, $0.1-1$ ) $\mathrm{cm}$. The tumor was localized to the tip of the appendix in 7 (87.5\%) and to the middle of the appendix in $1(12.5 \%)$ patient. The tumor had invaded the muscularis propria in 4 (50\%), the submucosa in $2(25 \%)$, the subserosa in 1 (12.5\%), and the mesoappendix in 1 (12.5\%) patient. All the patients had tumor-free margins and none of them had lymphadenopathy at diagnosis. The mitotic index and Ki-67 levels were $<2$ in $6(75 \%)$, three in 1 $(12.5 \%)$, and seven in $1(12.5 \%)$ patient. Histopathological images of a patient with mesoappendiceal invasion are shown in Figure 3.

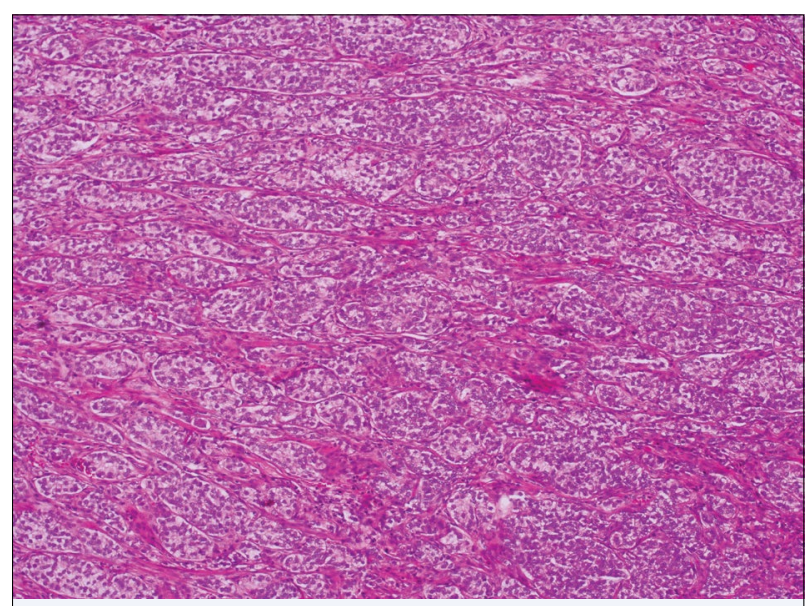

Fig. 1. Hematoxylin and eosin stain. Neoplastic carcinoid cell clusters $(\mathrm{HE} \times 10)$.

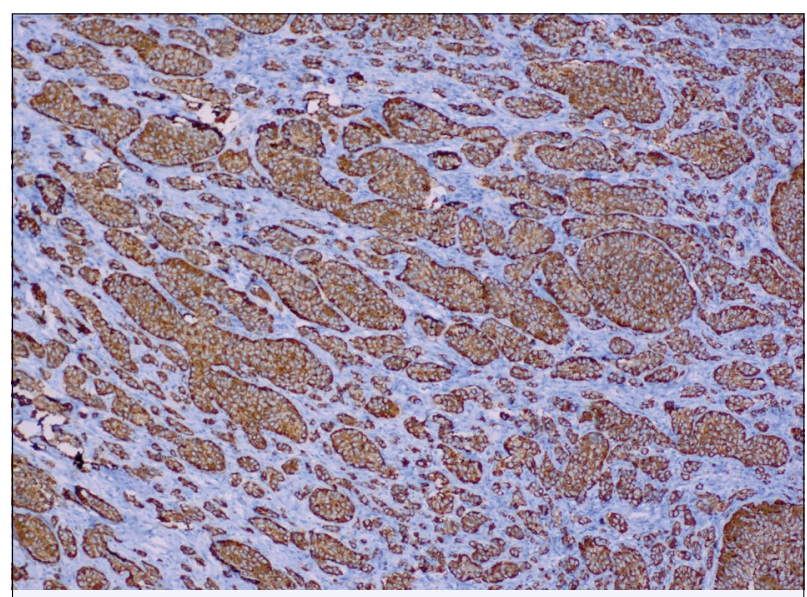

Fig. 2. Chromogranin immunostain. Diffuse positivity of carcinoid of the appendix (HEx10).

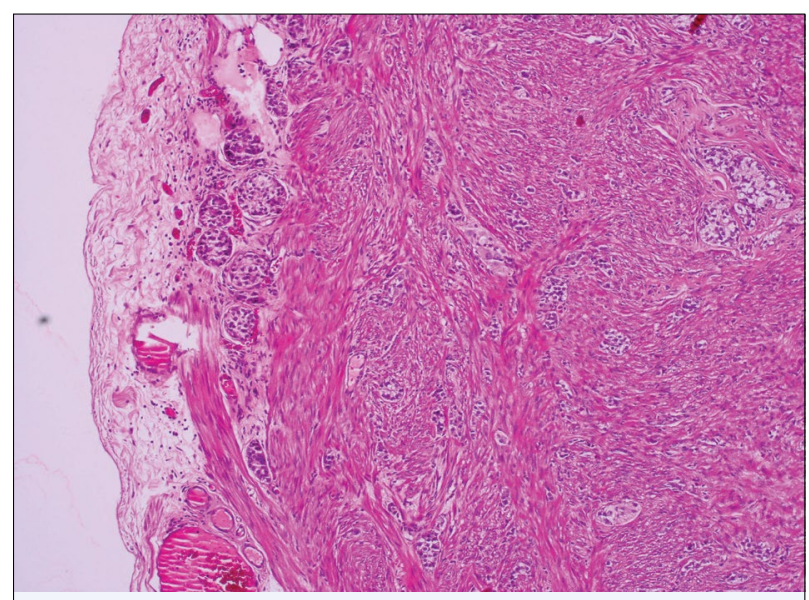

Fig. 3. Histopathological images of a patient with mesoappendiceal invasion $(\mathrm{HE} \times 4)$. 
Only appendectomy was performed in all patients. After the diagnosis, the patients underwent computer tomography and urine levels of 5-hydroxyindoleacetic acid (5-HIAA) were measured. All the patients were followed up every 6 months with abdominal tomography and urine 5HIAA tests (as per the decision of the council consisting of pediatric surgery, radiology, and pediatric oncology departments). No patient developed local recurrence, lymph node, or distant metastases during the follow-up period. Patients were followed up for a mean period of $41.2 \pm 11.1$ months. Demographic characteristics, histopathologic results, and the follow-up periods of the patients are shown in Table 1.

\section{Discussion}

Although ACT is a rare entity, it is the most commonly encountered neuroendocrine and intestinal tumor in children.[4,5] ACT is often diagnosed in childhood by the histopathological analysis of the appendix after appendectomy.[1] Similarly, in our study, all the patients were diagnosed after appendectomy. We consider that this phenomenon could be explained by the fact that the tumor does not reach large sizes in pediatric ages, US is preferred over tomography for radiographic evaluation, and distant metastasis is not commonly seen in children.

The incidence of ACT in our series was higher than in the present pediatric publications, which could be attributed to the reason that the incidence of malignancy varies not only among countries but also among regions. [6] On the other hand, a comparison with other studies was not possible since there is no such study on pediatric cases in Turkey.

In our patients, the most of the ACTs were localized to the tip of the appendix and the majority of the tumors were smaller than $1 \mathrm{~cm}$ in diameter. The prognosis and treatment of ACT is associated with tumor size and location, degree of invasion, mitotic and Ki-67 index, and the presence of perineural and lymphovascular invasion. $[7,8]$ The dilemma is what care should be taken following the incidental histological identification of an ACT. Different guidelines have been developed to assist decision making in such a situation.[3]

The 2010 World Health Organization classification divided ACT as G1 and G2 based on the mitotic and $\mathrm{Ki}-67$ index, both of which are accepted as predictors of metastasis and recurrence.[3] The North American Neuroendocrine Tumor Society and the European Neuroendocrine Tumor Society have recommended a right hemicolectomy for tumors with a diameter of $>2 \mathrm{~cm}$ or tumors with deep mesoappendiceal invasion. $[9,10]$ Moreover, the Eighth Edition (2017) of the American Joint Committee on Cancer Staging Manual added the invasion of the subserosa and mesoappendix, which had been omitted in the previous edition, into the diagnostic criteria of ACT. Accordingly, subserosa or mesoappendix infiltration identifies pT3 tumors and requires additional surgical methods in patients undergoing appendectomy.[11] Many pediatric clinics use these guidelines derived from adult experiences. $[3,12]$ In adult patients with ACT, 5-year mortality has been reported to be $29.5 \%$ for tumors $>2 \mathrm{~cm}$ and $5 \%$ for $<2 \mathrm{~cm}$. However, these tumors have been reported to behave differently in children and, in particular, have been shown to be mostly benign and to have excellent clinical outcomes. Moreover, the 5-year recurrence survival and overall survival rates have been reported as $100 \%$ in children.[3] On the other hand, it has been demonstrated that patients with a tumor size of $>2 \mathrm{~cm}$ have a 28 -fold higher risk of having a positive lymph node compared to patients with a tumor size of $\leq 2 \mathrm{~cm}$. However, this difference has been shown to be clinically insignificant in childhood.[3]

Recently, there have been a growing number of studies suggesting that the mitotic index does not correlate

Table 1 Demographic characteristics, histopathologic results, and the follow-up periods of the patients

\begin{tabular}{|c|c|c|c|c|c|c|c|}
\hline S. No. & $\begin{array}{l}\text { Age } \\
\text { (year) }\end{array}$ & Gender & $\begin{array}{l}\text { Tumor } \\
\text { location }\end{array}$ & $\begin{array}{l}\text { Depth of } \\
\text { invasion }\end{array}$ & $\begin{array}{l}\text { Tumor } \\
\text { size }(\mathrm{cm})\end{array}$ & Ki-67 & $\begin{array}{c}\text { Follow-up } \\
\text { time (month) }\end{array}$ \\
\hline 1. & 11 & Male & Tip & Subserosa & 0.9 & $>2(=7)$ & 64 \\
\hline 2. & 13 & Male & Tip & Mesoappendix & 0.4 & $<2$ & 56 \\
\hline 3. & 17 & Female & Tip & Muscularis propria & 0.1 & $<2$ & 11 \\
\hline 4. & 17 & Male & Tip & Muscularis propria & 0.2 & $<2$ & 19 \\
\hline 5. & 7 & Female & Tip & Muscularis propria & 0.3 & $<2$ & 38 \\
\hline 6. & 9 & Male & Tip & Muscularis propria & 1 & $<2$ & 43 \\
\hline 7. & 15 & Male & Tip & Muscularis propria & 0.2 & $<2$ & 46 \\
\hline 8. & 14 & Female & Middle & Subserosa & 0.5 & $>2(=3)$ & 52 \\
\hline
\end{tabular}


with overall survival.[12] Boxberger et al.[13] found no difference between pediatric patients with and without lymph node metastasis with regard to mean Ki-67 proliferation index. In our study, only two patients had a high mitotic index, who did not undergo additional surgical procedures and had no signs of recurrent or residual disease throughout the follow-up period.

Mesoappendiceal invasion used to be a common indication for hemicolectomy; however, numerous recent studies have shown that patients with mesoappendiceal invasion can achieve long-term survival without hemicolectomy.[3,4,12] In addition, some studies indicated that the degree of invasion had no effect on the clinical outcomes in pediatric children.[4] On the other hand, the right hemicolectomy is a significant abdominal procedure with an increased risk of complications, namely, gastrointestinal tract-related complications including ileus, anastomotic leak, stricture, and rarely ureteral injuries. Moreover, patients may even have permanent intestinal motility issues due to the loss of the ileocecal sphincter.[4] In our study, no additional surgery was performed in the patient who had mesoappendiceal invasion and the patient had no signs of recurrent or residual disease throughout the follow-up period.

\section{Limitations of the Study}

The limitations of the study were that it was a retrospective study and the data were obtained from medical records of hospital. Another limitation was the limited follow-up period of the cases and the follow-up period not exceeding 5 years in any case.

\section{Conclusion}

ACT is a rare tumor in children usually presenting as an incidental finding during the histopathological examination of appendectomy specimen. Follow-up of histopathological results after appendectomy is of paramount importance. Appendectomy is curative, particularly in tumors smaller than $2 \mathrm{~cm}$ in diameter, and the clinical outcome is excellent after appendectomy.

Peer-review: Externally peer-reviewed.

Conflict of Interest: All authors declared no conflict of interest.

Ethics Committee Approval: The study was approved by the University of Health Sciences, Trabzon Kanuni Training and Research Hospital Clinical Research Ethics Committee (No: 2020/59, Date: 22/10/2020).
Financial Support: This study has received no financial support.

Authorship contributions: Concept - S.S.; Design - S.S.; Supervision - S.S.; Funding - None; Materials - S.S., B.K.O.; Data collection and/or processing - S.S., B.K.O.; Data analysis and/or interpretation - S.S., B.K.O.; Literature search S.S., B.K.O.; Writing - S.S.; Critical review - S.S., B.K.O.

\section{References}

1. Sushma S, Prasad CS, Kumar KM. An unusual case of appendiceal carcinoid tumor in a child-case report. Indian J Surg Oncol 2016;7(1):95-7.

2. Ranaweera C, Brar A, Somers GR, Sheikh F, Pierro A, Zani A. Management of pediatric appendiceal carcinoid: A single institution experience from 5000 appendectomies. Pediatr Surg Int 2019;35(12):142730.

3. Njere I, Smith LL, Thurairasa D, Malik R, Jeffrey I, Okoye B, et al. Systematic review and meta-analysis of appendiceal carcinoid tumors in children. Pediatr Blood Cancer 2018;65:e27069.

4. Parikh PP, Perez EA, Neville HL, Hogan AR, Sola JE. Nationwide overview of survival and management of appendiceal tumors in children. J Pediatr Surg 2018;53(6):1175-80.

5. Kim SS, Kays DW, Larson SD, Islam S. Appendiceal carcinoids in children--management and outcomes. J Surg Res 2014;192(2):250-3.

6. Bahat Z, Kandaz M, Memis Y, Canyllmaz E, Kavgacı $\mathrm{H}$, Yoney A. Multıple primary malignant neoplasms from Eastern Black Sea Region of Turkey: Single center experience. Nobel Med 2016;12(2):13-9.

7. Doede T, Foss HD, Waldschmidt J. Carcinoid tumors of the appendix in children--epidemiology, clinical aspects and procedure. Eur J Pediatr Surg 2000;10(6):372-7.

8. Barut B, Gönültaş F. Carcinoid tumors of appendix presenting as acute appendicitis. Ulus Travma Acil Cerrahi Derg 2019;25(5):510-3.

9. Plöckinger U, Couvelard A, Falconi M, Sundin A, Salazar R, Christ E, et al. Consensus guidelines for the management of patients with digestive neuroendocrine tumours: Well-differentiated tumour/carcinoma of the appendix and goblet cell carcinoma. Neuroendocrinology 2008;87(1):20-30.

10. Boudreaux JP, Klimstra DS, Hassan MM, Woltering EA, Jensen RT, Goldsmith SJ, et al. The NANETS consensus guideline for the diagnosis and management of neuroendocrine tumors: Well-differentiated neuroendocrine tumors of the jejunum,ileum, appendix, and cecum. Pancreas 2010;39(6):753-66.

11.Sommer C, Gumy Pause F, Diezi M, Rougemont 
AL, Wildhaber BE. A national long-term study of neuroendocrine tumors of the appendix in children: Are we too aggressive? Eur J Pediatr Surg 2019;29(5):449-57.

12. Wu H, Chintagumpala M, Hicks J, Nuchtern JG, Okcu MF, Venkatramani R. Neuroendocrine tumor of the appendix in children. J Pediatr Hematol Oncol 2017;39(2):97-102.

13. Boxberger N, Redlich A, Böger C, Leuschner I, von Schweinitz D, Dralle H, et al. Neuroendocrine tumors of the appendix in children and adolescents. Pediatr Blood Cancer 2013;60(1):65-70. 